presented, I had made the diagnosis that this child was suffering from meningitis, and predicted that he would die in a few hours, and that if we could secure a necropsy we should find the evidences of inflammation both on the convexity and at the base of the brain. These predictions were absolutely verified, and I believed then, and I believe still, that the diagnosis was thereby fully sustained. Notwithstanding these facts, Dr. Chase considered the case to be one of hydrophobia. But was it? Let others judge for themselves. For my own part, as I have said, I firmly believe that it was a case of meningitis, and I felt at the time, and feel yet, that this experience justified, in the first crucial test to which they were subjected, the views which are expressed in the paper on the "Disorders mistaken for Hydrophobia," which was then so soon to be made public. 1 eningitis was one of the disorders about which I had not felt it necessary to argue much, because I thought that little argument would be needed. And yet, as I have said, the gentleman who called me to his assistance in this case insisted then, and still insists-against the evidence, as I believe, and in a line with what, without wishing to be invidious, I would designate as the popular impression-that it was a case of hydrophobia. I will admit that it has as many marks of genuineness as a vast number of the reported cases of hydrophobia. But here is just the trouble. It illustrates the greatest difficulty in getting at a scientific idea as to the nature of this disorder. The usual rule seems to be that, given a certain series of convulsive phenomena with unwillingness to swallow, which are not controlled by ordinary or even by extraordinary measures, and followed shortly by death, the case is one of hydrophobia. If it is followed by recovery it is said to be spurious hydrophobia. The fact that the patient was bitten by a mad dog is confirmatory of, but not indispensable to, the diagnosis. The madness of the dog, and even the fact of a bite or lick, may be assumed from the phenomena presented by the patient. This I believe to be the source of grave errors. If ever we are to have an accurate scientific understanding of what goes by the name of hydrophobia or rabies in men or in animals, we must first learn to define these terms better than they have ever yet been defined. I cannot repeat here what I have elsewhere considered in detail $;^{3}$ but I desire briefly to state that I have found that there are no essential differences in the clinical phenomena or issue of cases of so-called hydrophobia attributed to the most various causes: to the bites of a great variety of animals, rabid and healthy, including birds, fleas, and lice (Bollinger, Jolly); to the bites of human beings; to germs distributed in the earth and air (Doléris); to the kissing of a mad dog before it was hung (Bardsley); to drinking the milk of a rabid animal, to suckling (Roucher), and to coitus (Bollinger); to the handling of sabres used in killing rabid dogs (Virchow); and, finally, to a spontaneous origin, the most recent illustration of which was a patient who died under the care of Dr. Dujardin-Beaumetz, in Paris, in January of this very year. In one of the papers already mentioned I have described the occurrence of the symptoms of hydrophobia in a large number of disorders, and I here only refer to it for one of the most interesting and important phases of this literally vital question.

I cannot conclude without saying something in regard to the curability of hydrophobia. My studies have led me to the conviction that the prevailing despair as to the issue of this disorder is a sad mistake. Whatever hydrophobia may be, it cannot be said to be incurable. As genuine cases have recovered as have ever died. There is no better evidence for believing in the occurrence of hydrophobia than there is for believing it has been and can be cured. It is not consistent to hold to the one and to deny the other. To call cases that recover spurious is to beg the question. If there is a definition of hydrophobia which can be said to bear the stamp of authority, it fits a large number of cases which have recovered; and to assume that the disorder is always fatal is to select the worst way either to understand or to combat it. In fact, I think we shall have better notions in regard to the whole subject of hydrophobia, if we compare the disorder to convulsions, and use the word "hydrophobia" just as we do the word "convulsions," to describe a series of phenomena which may be due to various

${ }^{3}$ Remarks on Hydrophobia: Proceedings of the Philadelphia County Medical Society, vol.v.; and Philadelphia Medical Times, Aug. 11th, 1883 . Criticisms on the Specific Theory of Hydrophobia : Transactions of the College of Physicians of Philadelphia, third series, vol. vii.; and New York Xedical Journal, Dec. $29 \mathrm{th}, 1883$. causes. In some cases these causes as yet elude detection in others a careful search will lead to their discovery. A rational method of treating what is called hydrophobia will never, I believe, be established until we recognise the fact that it is not a single morbid entity, not a specific inoculable disease, but, like convulsions, a series of phenomena, the first step to the treatment of which must consist in remembering that it may be due to a great many different causes, and in endeavouring to find out what is the cause in each particular case. In many cases it will be possible to discover some disease of which the hydrophobic symptoms are merely epiphenomena. This done, the prognosis and the treatment must be made to conform to the diagnosis. When this becomes a custom, we shall less often have deaths from acute meningitis, or pericarditis, or tetanus, or mania-à-potu, or acute mania of any kind, unjustly charged to hydrophobia. Nor shall we then hear so regularly of the fruitless administration of overwhelming doses of morphia, chloral, belladonna, or curare, which are as great a confession of the impotence of medical art as are the violent measures of restraint which are so often employed, and but little less a confession of this impotence than is the act of smothering a patient to death, which is said to have been practised in this year of grace in the State of New York !

NOTES ON A CASE OF

\section{CIRRHOSIS OF THE LIVER PRESENTING} UNUSUAL POINTS OF INTEREST.

\section{BY SURGEON-MAJOR F. P. STAPLES,} MEDICAT STAFF.

A short while since 1 was asked by my friend Dr. Patron, of this city, to see in consultation with him H. R-, a young man sixteen years of age, suffering from ascites, and who had been ill with that symptom for about two months. With the exception of the abdominal superficial veins not being much enlarged, the clinical characters of the dropsy were those of liver cirrhosis, and this opinion was strangely supported by the family history of the patient. Twelve months previously an elder brother had died of that disease, and a necropsy had confirmed the diagnosis; about a year previously to that event a sister succumbed to the same malady, and in her case also the disease of the liver was verified by post-mortem examination. In the case under notice the onset of the disease was very insidious, and it was not marked in any way by pain or other symptom of acute disease. Its progresa was characterised rather by a gradual failure of health, and the first tangible symptom observed by his friends was his increasing abdomen. In coming to a diagnosis, we found some slight increase of the splenic dulness, and, as the patient had recently resided in a somewhat marshy district, Dr. Patron suggested an examination of the blood, to the results of which it will perhaps be most convenient next to allude. Altogether three examinations were made-viz., one at the period of the case first referred to, one about six weeks afterwards, and a third about ten days before death, which occurred in about three months from the date of the consultation. In the first examination there was an enormous excess of the colourless corpuscles, and these, without exception, apparently were covered with processes or projections which gave them the appearance of the dried fruit of the black pepper. I did not observe the amoboid movements of these processes described by Mr. Wharton Jones, but my examination was purely a clinical one, and, had it been sufficiently prolonged and repeated, no doubt I should have done so. In addition to these large cells, which almost filled the field of the microscope, there were also a number of molecules or granules, but the normal red corpuscles of the blood were not to be distinguished. In the second examination the large cells were still visible, but they had almost lost the cell or globular shape. They were for the most part somewhat triangular in outline, the processes forming the angles being more or less blunted, and the sides deviating somewhat, generally outwards, from the straight line. In the third examination the large cells had entirely disappeared, and the field was entirely occupied by amorphous particles in a plasma having a distinctly yellow colour.

It will be convenient next to complete the clinical history 
of the ease. From the period mentioned its progress was very rapid, and in about two months it was necessary to perform paracentesis. The usual relief to the embarrassed organs of the thorax followed this operation, but the patient suffered considerably from abdominal pain for about a week afterwards. The fluid reaccumulated with great rapidity, and in six weeks or thereabouts there was again necessity to tap him, but the performance of the operation was not desired by his relatives, and did not, in fact, from his then condition, seem advisable. Soon afterwards he was seized with hrematemesis and died within a few days, death being preceded by an unusually long comatose stage-about seventy-two hours.

The post-mortem examination extended only to the abdominal cavity, permission to make a limited dissection only having been received. The liver, which was moderately contracted, presented the appearance of an ideal specimen of the hobnail variety of cirrhosis. The surface tumours resembled unripe cherries in size and appearance, and on the surface of some of them tortuous bloodvessels were to be seen. On a deep section being made, the division of the organ into spherical lobules, corresponding in size to those visible externally, was well observed. The surface was free from adhesions or other evidence of a peripheral inflammation. Sections under the microscope corresponded in appearance with the illustrations (after Dreschfeld and Young) of this disease in the New Sydenham Society's Atlas of Pathology. The spleen was enlarged, but only to a moderate extent. There was no sclerosis of its tissue, but this was somewhat more soft and friable than normal.

Remarks.-The foregoing case would appear to offer for consideration the following points of special interestnamely: 1 . The age of the patient. 2. The fact of his having been the third successive member of the same family who died in adolescence from the disease in question. 3 . The abnormal condition of the blood. I am aware that there is nothing extraordinary in the age "of the patient, but still it is decidedly exceptional. It may be considered, further, in connexion with the second point, which seems to me to be a unique experience, and more especially when it can be alleged with absolute certainty that in none of the three cases was there a suspicion of any of those agencies with which we are accustomed to associate cirrhosis of the liver. It is to be recorded, however, in regard to one of those agencies, that there was a history of long-continued alcoholic excess on the part of the father of the children. It is true that his death, which took place about five years ago, was not due to liver disease, but to cerebral apoplexy; there is, however, a fair presumpision that in his case there were degenerative hepatic changes due to the cause under observation. Did he then transmit to his offspring a diathesis hereditarily determining cirrhotic atrophy of the liver? That seems a fair inference from the detailed medical histories of the children, but in relation to the broad question of pathology the question is a new one, to me at any rate; but if it be possible to answer it in the affirmative from the foregoing experience, it will serve to explain some of those anomalous cases of this disease in regard to which Frerichs has written the following pregnant sentence: "There are undoubtedly causes of cirrhosis with which as yet we are totally unacquainted." There is next to be considered the question of the condition of the blood, and under this heading it is perhaps necessary to allude to the diagnosis of the case. It may be said that the patient was the subject of two intercurrent diseases-viz., cirrhosis of the liver and splenic leucocythemia. Such an impression was entertained during the clinical progress of the case, but obviously it was not supported by the postmortem examination, and the blood-cells already described, although resembling those of leucocythemia, were larger and much more numerous than are generally the leucocytes, even in advanced splenic disease. How, then, is the condition of the blood to be accounted for? It is not expedient perhaps, in a scientific sense, to offer any explanation from a single case; but it is hoped rather that by placing it on record the attention of pathologists may be directed to a subject which does not yet appear to have received adequate investigation. Gibraltar.

Mr. George Fisher, M.B., C.M. Edin., a well known Scotch doctor, was found late on Sunday night lying dead on a sofa in his back shop at Millport, Island of Cumbrae. The cause of deathis as yet unknown.

\section{A CASE OF PUERPERAL CONVULSIONS, WITH COMPLICATIONS.}

BY W. TYRRELL BROOKS, M.B. LOND, PHISICIAN TO THE RADCLIFFE INFIRMARY, OXFORD.

ON Dec. 29th I was asked to see a case in consultation with Mr. Ballard of this town. The previous history was as follows. Mrs. T-, a young nervous woman, who had been under treatment at intervals for some years for neuralgia and other nervous affections, was expecting to be confined with her second child. On Dec. 19th she was seized with occasional convulsions, accompanied by pain and numbness of the right arm and leg, together with a slight dragging of the right leg in walking. The convulsions increased in severity until Dec. 22nd, when Mr. Ballard was sent for, who, finding the os uteri dilated and labour commenced, delivered the patient of a living child by instruments. After delivery the convulsions continued, but gradually became less severe. One convulsion occurred, however, of a much longer duration than the rest, after which the right side of the body was found to have become weaker than the corresponding side, and in a short time to have become completely paralysed. The convulsions after this became less frequent, and, instead of being general, were now limited to the upper part of the body. The last convulsion occurred on the sixth day after delivery. Ever since her confinement the patient had lain in a state of apathy, without speaking or taking notice of her surroundings. She, however, took readily a considerable quantity of liquid food, though she swallowed with a little difficulty. At first she passed her urine and fæces normally, but on the sixth day after delivery she began to pass them under her.

When I saw her on Dec. 29th she was lying in a state of unconsciousness. When spoken to sharply she endeavoured to put her tongue out, but failed. She followed my movements round the bed with her eyes, but would not follow the movements of my hand when asked to do so. The right leg and arm were completely paralysed, but had not lost sensation. On pricking the right arm or leg with a pin, she uttered a cry of pain, but did not speak, and drew away the corresponding member of the opposite side. Sensation on the left side was unimpaired. She expressed considerable pain when her right leg or arm was suddenly moved. The neck was extended and stiff, and any attempt to flex the head on the chest was resisted, the act being attended with considerable pain to the patient. The pupils were equal and reacted to light. There was not any evidence of facial paralysis. The pulse was 120 , tense and hard; the heart sounds normal ; respiration 36 , rapid and shallow. Over the whole of the upper lobe of the right lung there was bronchial breathing with fine expiratory crepitation. The lochia had continued for three or four days after confinement and then ceased. The tongue was coated and the teeth covered with sordes. The temperature was $101^{\circ}$.

When I saw her again on Dec. 31st there was considerable improvement in the general condition. She had spoken since my last visit, and appeared more sensible. The urine and fæces had been passed normally. The pulse was 120 , but much softer; temperature $99.5^{\circ}$; respiration 36 . Over the upper lobe of the right lung there was bronchial breathing with abundant crepitation. On Jan. 1st the improvement was still more marked. She answered questions slowly and hesitatingly, but her articulation was perfect. The breath sounds over the right pulmonary upper lobe were softer, and the crepitation still abundant. Respiration 30 ; pulse 120 ; temperature $99.5^{\circ}$. There was slight movement of the muscles of the upper part of the right arm and of the right leg. She complained of pain in the head, running down the back of the neck, and although the head could be flexed on the chest, it was accompanied by much pain, together with resistance of the cervical muscles.

On Jan. 4th the patient was practically convalescent. The respiratory sounds over the upper lobe of the right lung were almost vesicular, and the crepitation much diminished. The temperature was normal ; pulse 108; respiration 30 There was increased power in the right upper arm and leg, and also some movement of the left lower arm. The patient, though kept scrupulously clean by the nurse, had 